\title{
On the mechanisms and kinetics of evaporation of a compacted silt
}

\author{
Régis Mpawenayo ${ }^{1, a}$, Frédéric Debaste ${ }^{2}$, Madjid Douzane ${ }^{1}$, Pierre Gerard ${ }^{1}$ \\ ${ }^{1}$ Université libre de Bruxelles (ULB), BATir Department, Laboratory of GeoMechanics, Brussels, Belgium \\ ${ }^{2}$ Université libre de Bruxelles (ULB), TIPs Department, Brussels, Belgium
}

\begin{abstract}
In order to define a convective evaporation model able to reproduce the evaporation rates according to the atmospheric conditions, drying tests have been performed on cylindrical samples of a compacted silt in a closed chamber where the relative humidity of the air is controlled by means of saturated saline solutions. Calibrating such models using experimental results from small sample sizes can indeed be an interesting alternative to simplify the experimental procedures and to reduce the test duration in comparison with the standard in-situ tests (e.g. lysimeter). However the influence of the size of the samples on the kinetics of evaporation has to be investigated. Samples with different diameters and heights are therefore tested. The results show that the observed mechanisms of drying are similar to those at the scale of the geostructure if the dimensions of the sample are higher than a critical height and a critical diameter. We show then that the experimental critical height is consistent with the concept of critical length proposed by Lehman et al. (2008), who expresses analytically when the hydraulic connection between the sample surface and the drying front is upset. Finally the kinetics of evaporation recorded under different relative humidities highlight that the mass transfer coefficient defined in the convective evaporation model does not depend on the relative humidity.
\end{abstract}

\section{Introduction}

Soil-atmosphere interactions relate to the moisture transfers occurring between a geomaterial and its surroundings. These transfers of moisture between the soil and atmosphere include infiltration, evaporation, evapotranspiration and runoff. The understanding and quantification of these transfers is a crucial issue in many civil engineering applications: slope stability problems, soil cover systems for waste materials or constructions built on expansive clay. In this paper, we focus on the mechanisms of evaporation in soils.

It is now admitted that the experimental evaporation rates measured can be successfully reproduced numerically by means of vapour flux at the soil surface equal to the product of a driving force (the difference between the vapour density at the interface and of the surroundings) and a mass transfer coefficient characterizing the resistance of a boundary layer where the exchanges with the surroundings take place $[1,2]$. Some correlations between the evaporation rates and the climatic conditions, as the wind speed, the air relative humidity and temperature, have been determined [3, 4, 5, 6]. Many of these correlations are calibrated using tests carried out in situ or in an environmental chamber [7, 8, $3]$. The main drawback of field-scale experiments is that atmospheric conditions are naturally changing, which makes difficult separating the influence of ambient conditions and soil properties on the evaporation rate measurement. To avoid this drawback, it is proposed to perform drying tests in laboratory where atmospheric conditions are controlled. Environmental chamber provides a relevant solution [7], but the large volume of soil $\left(1 \mathrm{~m}^{3}\right)$ tested increases the time needed for the soil preparation and installation, as well as the test duration. It is why it is proposed to perform laboratory drying tests on small samples with different sizes. The question of the influence that could have the sample sizes (the evaporation surface and the height of the sample) on the kinetics of evaporation is not well documented. This raises the question of knowing the minimal dimensions of the samples needed to obtain relevant evaporation rates useable for large-scale applications.

This paper proposes to carry out an experimental campaign focusing on the effect on the influence of the sample dimensions on the kinetics of evaporation and especially on the mass transfer coefficients. A drying chamber where the relative humidity is controlled by means of saturated saline solutions is developed and allows performing evaporation tests without any forced convection. This paper proposes also new insights into the evaporation process at soil surface and the understanding of the boundary layer mechanisms.

\footnotetext{
armpawena@ulb.ac.be
} 


\section{Material and methods}

\subsection{Material and sample preparation}

The soil examined in this research is a sandy silt from Marche-les-Dames (Belgium) (Unified Soil Classification System (USCS)). Its index properties are: liquid limit $\left(w_{L}\right)=32.5 \%$; plasticity index $(I P)=15 \%$. The grainsize distribution is: $13 \%$ of clay, $64 \%$ of silt and $26 \%$ of sand. The permeability of the saturated silt compacted first at the Optimum Proctor compaction conditions (initial water content $w_{0}=14.8 \%$; initial dry density $\rho_{d 0}=$ $18.40 \mathrm{kN} / \mathrm{m}^{3}$ - see [9] for more details) and then resaturated is equal to $10^{-10} \mathrm{~m} / \mathrm{s}$. The determination of the retention curve of the silt is based on the use of 2 techniques: the pressure plate apparatus [10] and the vapour transfer technique [11]. Experimental data are presented in Figure 1, where a van Genuchten model [12] has been fitted on the data.

$$
S_{r}=\left[1+\left(\frac{s}{P_{r}}\right)^{n}\right]^{-(1-1 / n)}
$$

with $P_{r}=1000 \mathrm{kPa}$ and $n=1.4$.

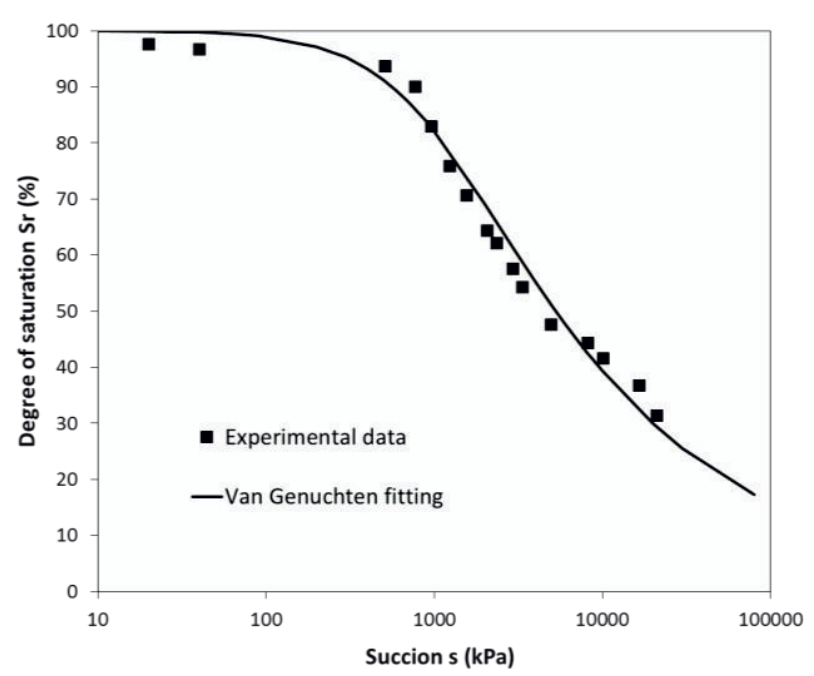

Figure 1. Retention curve of Marche-les-Dames silt:

experimental data and fitting of van Genuchten relationship.

Soil samples with different dimensions (diameter $D=15 ; 35 ; 50 \mathrm{~mm}$ - height $H=15 ; 25 ; 45 ; 70 \mathrm{~mm}$ ) are prepared at the optimal compaction conditions. For samples with a final height of $15 \mathrm{~mm}$ specimen are statically compacted in oedometer cell $(D=50 \mathrm{~mm} ; H=15$ $\mathrm{mm}$ ) and then saturated in oedometer cell. When saturated conditions are met the samples are cut with hollow cylinder cutter of different diameters. For samples with a final height higher than $15 \mathrm{~mm}$ specimen are statically compacted in triaxial mold $(D=35 \mathrm{~mm} ; H=70$ $\mathrm{mm})$. Samples are then saturated in a triaxial cell with a confining pressure of $60 \mathrm{kPa}$ and a water pressure of 50 $\mathrm{kPa}$ applied on the top of the sample. The saturation is reached when the flowrate of water injected in the sample through lower porous stone is equal to the flowrate of water measured through the upper porous stone.

In order to create drying conditions as close as possible to 1D flow all the core of saturated samples are covered with a plastic film and aluminium foil and finally wrapped with a paraffin layer to prevent evaporation from the base and lateral surfaces of the samples and to minimize the lateral water flow (Figure 2).

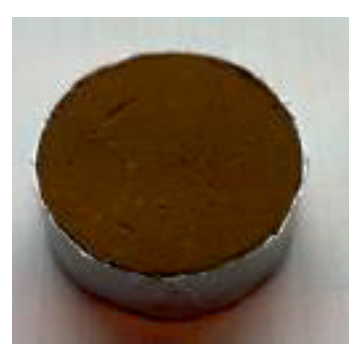

Figure 2. Imposition of 1D vapour transfers within the sample.

\subsection{Experimental methods}

The principle of the determination of the mass transfer coefficients is based upon measurements of mass loss of a sample during drying test. So, a drying chamber without any forced convection has been developed. A cylindrical sample (initially saturated) is introduced inside a hermetic chamber in which the relative humidity $(R H)$ is maintained. A saturated saline solution has been used to control the relative humidity in the chamber thanks to vapour transfer technique [11]: $\mathrm{MgCl}_{2}$ $(R H=33 \%)$. The samples are placed on a stand that hangs above the saline solution and that is connected to a weighing machine (Figure 3). Some tests are performed on very small samples, which implies the use of a highprecision weighing machine (accuracy $0.0001 \mathrm{~g}$ ). The mass loss is recorded every $5 \mathrm{~min}$.

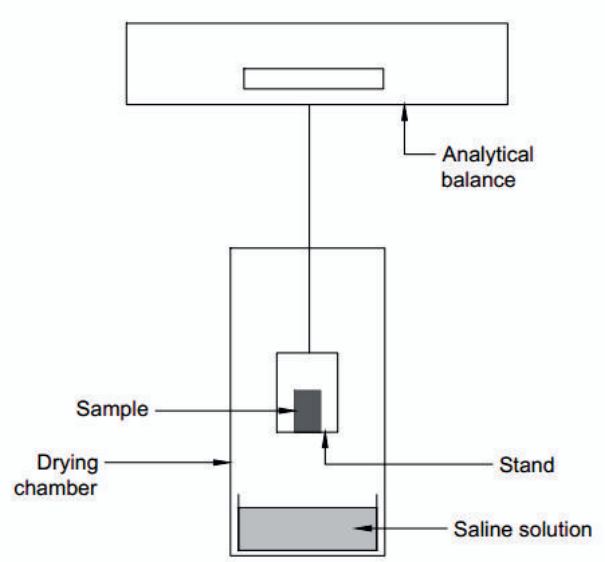

Figure 3. Schematic representation of the set-up for drying without any forced convection.

\subsection{Data treatment}

Experimental data of evolution of sample mass $M(t)$ as a function of time $t$ are treated to present the Krischer curve, i.e. the drying rate $q\left(\mathrm{~kg} \cdot \mathrm{m}^{-2} \cdot \mathrm{s}^{-1}\right)$ as a function of 
the water content $w$. The drying rate $q$ at a given time is calculated as follows:

$$
q=\frac{M(t)-M(t-\Delta t)}{A \Delta t}
$$

where $\Delta \mathrm{t}$ the time interval between two measurements, $A$ is the area of the external surface of the sample that contributes to the evaporation.

The drying rate calculated based on equation (2) is filtrated using Lanczos method [13] to reduce noise generated by the subtraction between two mass measurements that only differ from an order of magnitude slightly larger than the weighing measurement error. The obtained curve highlights the two classical distinct drying stages [14, 15]. The stage I, for water content between the initial water content $w_{0}$ and a lower limit value called the critical water content $w_{c}$, shows a constant drying rate $q_{\max }$. During this stage, the soil surface is at or near saturation and the evaporation rate is limited by the diffusion in the external boundary layer. The second period, for water content lower than the critical value, shows a falling drying rate that corresponds to a limiting and growing internal mass transfer resistance. Stage II of drying starts when the internal conductive properties of the soil (permeability, diffusivity) do no longer allow a sufficient water flow to the soil surface to maintain the maximal evaporation rate. Therefore, the transition between the two periods, around the critical water content, expresses the progressive development of an internal mass transfer resistance in series to the previously limiting external mass transfer resistance $[13,16]$.

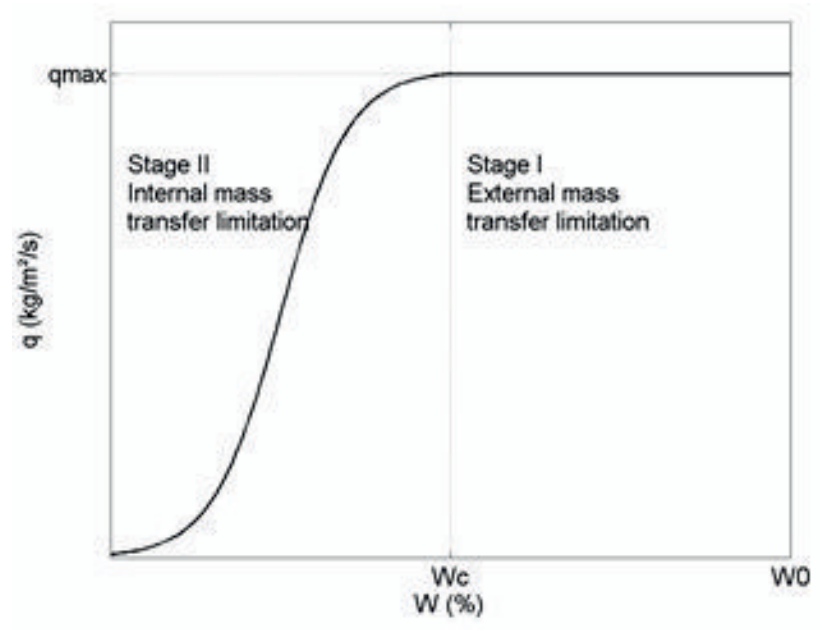

Figure 4. Typical Krischer curve highlighting Stage I $(w>w c)$ and stage II $\left(w<w_{c}\right)$.

From the Krischer curves obtained, the maximal drying rates and the critical water contents $w_{\text {crit }}$ are deduced. For stage I, the constant mass transfer coefficient $\alpha$ can be evaluated based on the value of $q_{\max }$ and assuming a saturated surface at the sample top [17].

$$
q_{\max }=\alpha\left(\rho_{v, 0, \text { sample }}-\rho_{v, \text { air }}\right)
$$

So the mass transfer coefficient is given by:

$$
\alpha=\frac{q_{\max }}{\left(\rho_{v, 0, \text { sample }}-\rho_{v, \text { air }}\right)}
$$

with $\rho_{v, 0 \text {, sample }}$ the saturated vapour density at soil surface which depends only on the temperature of the interface.

Various empiric or thermodynamics expressions allow to evaluate this dependence. In this work, the correlation from [18] is used:

$$
\frac{1}{\rho_{\mathrm{v}, 0}}=194.4 \exp \left(-0.06374 T+0.163410^{-2} T^{2}\right)
$$

with $T$ the temperature $\left({ }^{\circ} \mathrm{C}\right)$.

As evaporation is an endothermic process, the local interfacial temperature is not necessarily equal to surrounding temperature. When the evaporation rate remains constant (the maximum evaporation rate $q_{\text {max }}$ ), the temperature at the sample surface is considered equal to the wet bulb temperature. The wet bulb temperature $T_{h}$ is calculated with the relationship [19]:

$T_{h}=\frac{\left[1810.9\left[p_{v, 0}\left(T_{h}\right)-p_{v}\left(T_{\text {air }}\right)\right]\right]-T_{\text {air }}\left[p_{a t m}-p_{v, 0}\left(T_{h}\right)\right]}{2 p_{v, 0}\left(T_{h}\right)-p_{v}\left(T_{\text {air }}\right)-p_{a t m}}$

with $T_{\text {air }}$ the air temperature $\left({ }^{\circ} \mathrm{C}\right), p_{\text {atm }}$ the atmospheric pressure, $p_{v, 0}$ the saturated vapour pressure and $p_{v}$ the vapour pressure.

\section{Results and discussions}

7 cylindrical samples of compacted silt with different diameters $D$ and heights $H$ have been dried in the drying chamber without any forced convection under air relative humidity $R H=33 \%$. The air temperature in the room where the tests are performed is constant and is equal to $24^{\circ} \mathrm{C}$. From the Krischer curves the maximal drying rates and the critical water contents $w_{c}$ are deduced. From equation (4) the mass transfer coefficients are calculated. Those different values characterizing the drying kinetics are reported in Table 1. 
Table 1. Experimental conditions and results of tests without forced convection.

\begin{tabular}{|c|c|c|c|c|c|c|}
\hline $\mathrm{N}^{\circ}$ & $\begin{array}{c}\text { Diameter } D \\
(\mathrm{~mm})\end{array}$ & $\begin{array}{c}\text { Height } H \\
(\mathrm{~mm})\end{array}$ & $\begin{array}{c}\text { Air relative } \\
\text { humidity } \\
R H \\
(\%)\end{array}$ & $\begin{array}{c}\text { Maximal drying } \\
\text { rate } q_{\max } \\
\left(\mathrm{kg} \cdot \mathrm{s}^{-1} \cdot \mathrm{m}^{-2}\right)\end{array}$ & $\begin{array}{c}\text { Mass transfer } \\
\text { coeffiient } \alpha \\
(\mathrm{m} / \mathrm{s})\end{array}$ & $\begin{array}{c}\text { Critical } \\
\text { water } \\
\text { content } w_{c} \\
(-)\end{array}$ \\
\hline 1 & 50 & 15 & 33 & $2.410-5$ & $5.3210^{-3}$ & 0.08 \\
\hline 2 & 35 & 15 & 33 & $3.010-5$ & $6.0610^{-3}$ & 0.09 \\
\hline 3 & 15 & 15 & 33 & $5.5010-5$ & $1.1110^{-2}$ & 0.10 \\
\hline 4 & 15 & 15 & 33 & $5.0010-5$ & $1.0110^{-2}$ & 0.10 \\
\hline 5 & 35 & 70 & 33 & $3.010-5$ & $6.8210^{-3}$ & 0.14 \\
\hline 6 & 35 & 45 & 33 & $2.810-5$ & $6.3710^{-3}$ & 0.11 \\
\hline 7 & 35 & 25 & 33 & $3.010-5$ & $6.8210^{-3}$ & 0.095 \\
\hline
\end{tabular}

\subsection{The influence of the sample surface on the kinetics of evaporation}

Soil samples with the same height $H=15 \mathrm{~mm}$, prepared under the same conditions but with different evaporation surfaces, were dried in the same drying chamber in the same relative humidity $R H=33 \%$ (Table $1, N^{\circ} 1$ to 4 ). The results show that the drying rate is higher for the samples with diameter $D=15 \mathrm{~mm}$ than for samples with diameter $D=35 \mathrm{~mm}$. But the evaporation flows for sample with $D=35 \mathrm{~mm}$ and sample with $D=50 \mathrm{~mm}$ are similar (Figure 5). The mass transfer coefficients also decrease from diameter $D=15 \mathrm{~mm}$ to $D=35 \mathrm{~mm}$, but then reach a plateau (Figure 6). The mass transfer coefficients remain indeed constant when diameter increases to $50 \mathrm{~mm}$. Physically, this can be explained by the development of the boundary layer around the sample surface, and especially along the edges. At the edge of the sample, evaporation can take place in both horizontal and vertical directions, while only vertical evaporation is allowed at the center of the top surface. The thickness of the boundary layer (and so the value of the local mass transfer coefficient) is therefore not constant all along the top surface, but the influence of this edge effect becomes negligible when the diameter increases (Figure 7). This is why the mass transfer coefficients determined experimentally on samples with diameters of 35 and $50 \mathrm{~mm}$ are equivalent, which is not the case with smaller diameters.

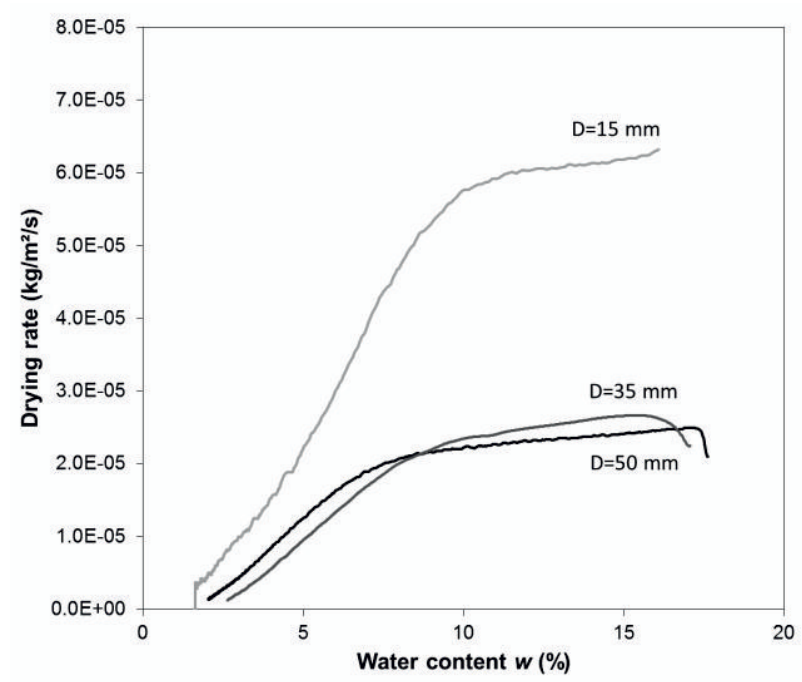

Figure 5. Influence of the sample surface on the drying rate $(\mathrm{H}=15 \mathrm{~mm}-\mathrm{RH}=33 \%)$
The same trend is observed on the values of the critical water contents (Table 1), where the values for small diameters $(15 \mathrm{~mm})$ are always higher than for the other dimensions. As the evaporation is high on the edges of the sample, it is there that the soil properties will first limit the evaporation rate. Once the soil properties begin to limit the evaporation rate at the sample edges, the second evaporation phase begins, which allows defining the critical water content. This decrease of the

evaporation rate is not uniform on entire evaporation surface because in the middle of the evaporation surface, there is still enough water to maintain maximum evaporation rate. The effect of the edge on evaporation rate is negligible for sample with large surface of evaporation.

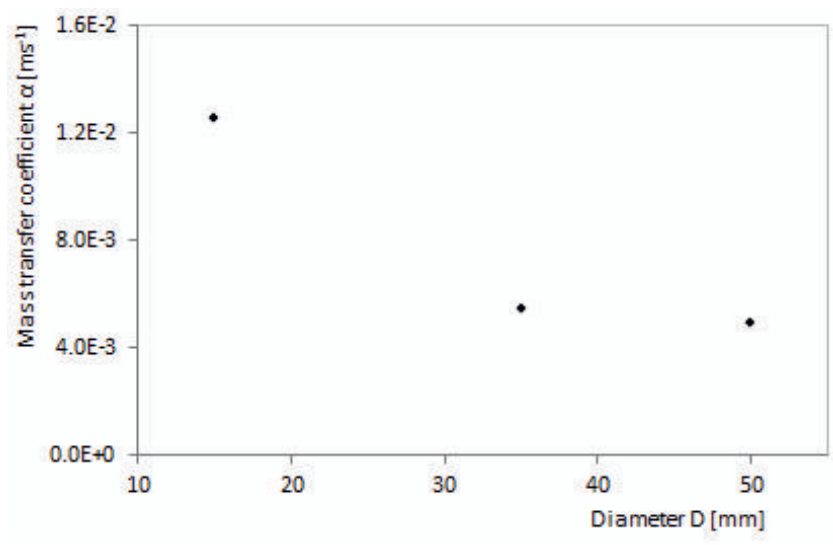

Figure 6. Influence of the sample surface the mass transfer coefficient

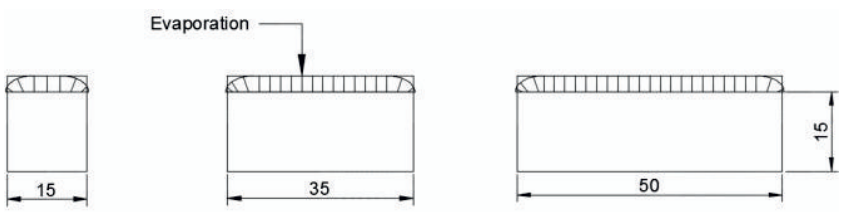

Figure 7. Development of the boundary layer at the surface Edge effect

\subsection{The influence of the sample height on the kinetics of evaporation}

The influence of the sample height is analyzed by the comparison of the drying rate of 4 samples with the same 
diameter $(D=35 \mathrm{~mm})$ and submitted to the same drying conditions $(R H=33 \%)$, but with different heights $(H=15$, $25,45,70 \mathrm{~mm}-$ Tests 2,5 to 7 in Table 1). Figure 8 and 9 present the drying rates of the different tests according to the time and the water content respectively. First the results show that the maximum drying rate $q_{\max }$ is not dependent on the sample height. On the other hand the critical water content $w_{c}$ is influenced by the sample height, as confirmed by the data from Table 1 . Finally the temporal analysis suggests that the curves drying rate vs. time are the same for heights of 45 and $70 \mathrm{~mm}$.

Those results are consistent with the concept of critical length affecting drying of porous media proposed by [20]. They considered that the transition between Stage I and Stage II of drying is explained by a modification of the fluid transfers mechanisms within the sample, from a liquid-flow based first stage to a second stage controlled by vapor diffusion through the sample and the receding of a drying front. The critical length determines the maximal extent along which water can flow to ensure a hydraulic connection between the sample surface and this internal drying front. They proposed a relation to estimate this critical length based on the equilibrium between upwards capillary forces and downwards viscous and gravity forces to whom are submitted the interstitial water.

$$
\Delta h_{\text {cap }}=\Delta h_{\text {visc }}+\Delta h_{\text {grav }}
$$

with $\Delta h_{\text {cap }}, \Delta h_{\text {visc }}, \Delta h_{\text {grav }}$ the capillary, viscous and gravity head differences respectively.

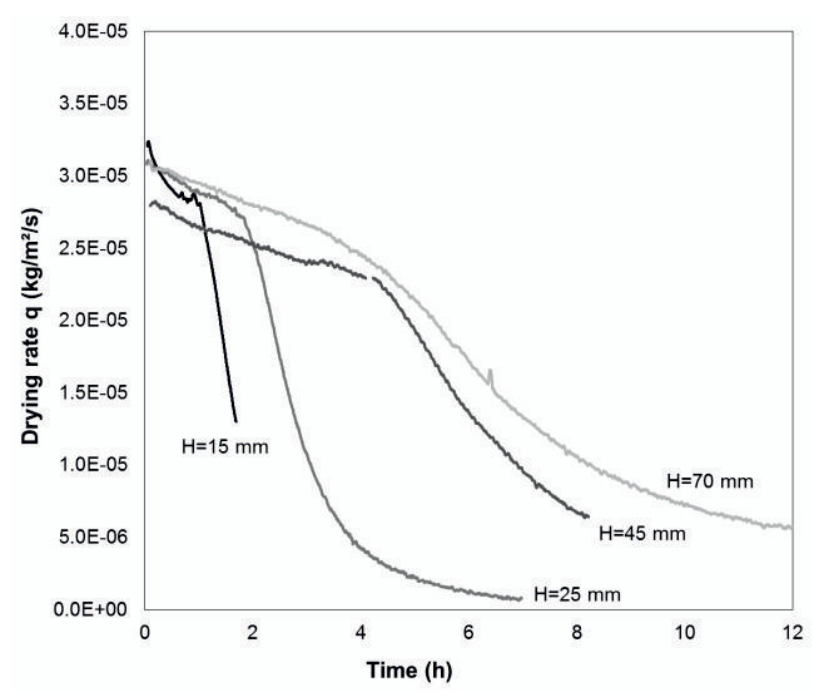

Figure 8. Drying rate according to the time for different sample heights $(D=35 \mathrm{~mm} ; R H=33 \%)$.

The capillary head difference is affected by the soil microstructure. [20] proposed to consider the slope of the tangent to the retention curve at the inflection point to estimate the capillary pressure difference. Using a van Genuchten retention model (equation1), the capillary head difference can be obtained from (more details in [20]) by equation 8 .

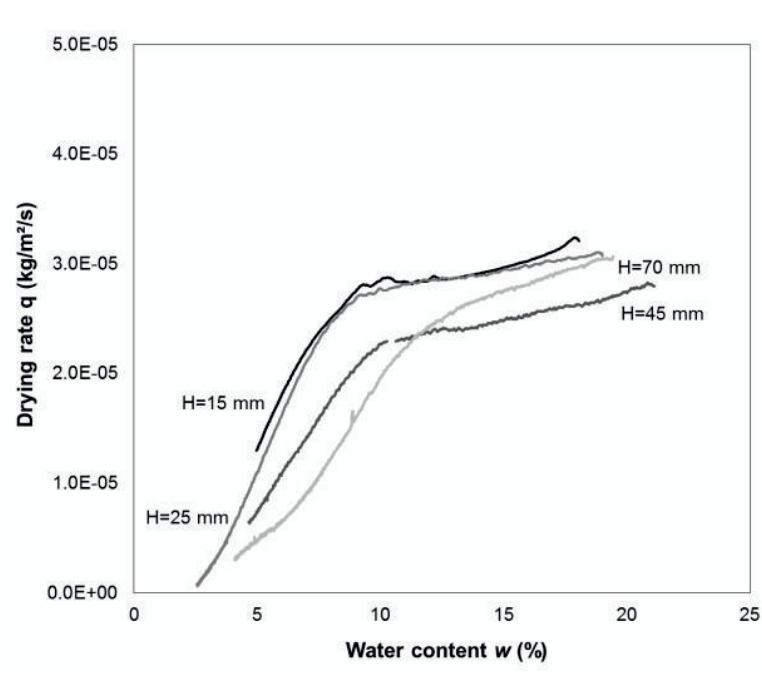

Figure 9. Drying rate according to the water content for different sample heights $(D=35 \mathrm{~mm} ; R H=33 \%)$.

$$
\Delta h=\frac{P_{r}}{n-1}\left(\frac{2 n-1}{n}\right)^{(2 n-1) / n}\left(\frac{n-1}{n}\right)^{(1-n) / n}
$$

with $P_{r}$ and $n$ the parameters of the van Genuchten retention model (equation 1).

The viscous forces are estimated from the Darcy law for unsaturated flow. They depend on the maximal drying rate, which is itself influenced by the atmospheric conditions.

$$
\Delta h_{\text {visc }}=\frac{L_{c r i t} q_{\max }}{\bar{K}\left(S_{r}\right) \rho_{w}}
$$

with $L_{c r i t}$ the critical length, $\mathrm{q}_{\max }$ the maximum drying rate, $\rho_{w}$ the water density, $\bar{K}\left(S_{r}\right)$ the mean hydraulic permeability (which depends on the degree of saturation $S_{r}$ ) between the surface and the drying front assuming a hydrostatic water content distribution above the drying front.

The gravity forces depend only on the distance between the drying front and the surface, which corresponds to the critical length.

$$
\Delta h_{\text {grav }}=L_{c r i t}
$$

The characteristic length can be finally expressed as:

$$
L_{c r i t}=\frac{\Delta h_{c a p}}{1+\frac{q_{\max }}{\rho_{w} \bar{K}\left(S_{r}\right)}}
$$

For a diameter of $35 \mathrm{~mm}$, the maximal drying rate is about $310^{-5} \mathrm{~kg} \cdot \mathrm{s}^{-1} \cdot \mathrm{m}^{-2}$ whatever the sample height (Table $1)$. From the equation 1 and the permeability of the soil under saturated conditions, the mean hydraulic permeability can be obtained from the Mualem 
relationship [21], which expresses the permeability as a function of the degree of saturation $S_{r}$ :

$$
K\left(S_{r}\right)=K_{s a t} \sqrt{S_{r}}\left[1-\left(1-S_{r}^{1 /(1-1 / n)}\right)^{1-1 / n}\right]^{2}
$$

with $K_{\text {sat }}$ the permeability under saturated conditions, $n$ a parameter equal to the equivalent van Genuchten parameter (equation 1).

If we apply the equation 11 to the drying experiments presented in this paper, we find a characteristic length of the hydraulic connection $L_{\text {crit }}$ about $40 \mathrm{~mm}$. Owing to the assumptions used in the Lehman's methodology (capillary forces estimated from the retention curve, water content distribution between the drying front and the surface, etc.), only an order of magnitude of the characteristic length can be obtained with this relationship. However this value of $40 \mathrm{~mm}$ is consistent with the experimental observations in Figure 8 and 9:

i. When the height of the samples is larger than the characteristic length, the Stage II of drying is explained by the end of the hydraulic connection within the sample. The critical water content is therefore dependent on the amount of water available within the sample when the hydraulic connection is broken. Because the characteristic length is not dependent on the sample height, the critical water content increases with the height as observed in Figure $9(H=45 \mathrm{~mm} ; H=70 \mathrm{~mm})$.

On the other hand the same duration of stage $I$ is expected when the sample height is larger than the characteristic length, because the maximal drying rate is not influenced by the height. This is confirmed experimentally in Figure $8(H=45 \mathrm{~mm} ; H=70 \mathrm{~mm})$.

ii. When the height of the samples is smaller than the characteristic length, capillarity forces are strong enough and gravity and viscous forces have no direct impact on the critical water content. Rather, the hydraulic connection is lost when a first region of the bottom of the sample is dried: the breakthrough [22]. For cylindrical samples with no lateral evaporation like in our case, this breakthrough should appear at a water content that varies only slowly with the sample height [22]. Thus the critical water content should be independent on the sample height. Even if the conclusions on drying kinetics drawn from samples with a height smaller than the critical length are consistent (Figure 7 for example), values of critical water contents from those tests can thus probably not directly transferred to large-scale evaporation kinetics problems.

\section{Conclusions}

Drying tests have been performed to study the influence of sample dimensions on the kinetics of evaporation. For cylindrical soil sample, we showed that the drying surface does not have any influence on the maximum drying rate and the mass transfer coefficient for diameters greater than $35 \mathrm{~mm}$. The results highlight also that the slenderness of the sample does not have any influence on the drying rate and the mass transfer coefficient, but affects the transition from the stage I to the stage II (critical water content). These observations allow us proposing a set of guidelines on the dimensions of the soil samples to test in order to reproduce drying mechanisms similar to those observed on geostructures at large field-scale:

- When the analysis of the drying kinetics is related to the maximum evaporation flux and mass transfer coefficient, the optimal sample must have a diameter greater than or equal to $35 \mathrm{~mm}$, regardless of the sample height.

- If the study is also related to the time and the critical water content, the samples must have, in addition to a diameter greater than $35 \mathrm{~mm}$, a sample height higher than the critical length is needed. This critical length depends on the soil type and the drying conditions.

\section{References}

1. D.M. Gray, Can. Nat. Com. for the Intern. Hydr. Dec., (1970)

2. G.W. Wilson, D.G. Fredlund, and S.L. Barbour, Can. Geotech. J. 31(2), 151-161 (1997)

3. H. L. Penman, Math., Math. Phys. Eng. Sci. 193, 120-145 (1948)

4. T. Yamanaka, A. Takeda, F. Sugita, Water Resour. Res. 33(9), 2117-2128 (1997)

5. D.E. Blight, Géotechnique, 47(4), 715-767.

6. J. Teng, N. Yasufuku, Q. Liu, S. Liu, Nat. Hazards, 73, 1405-1418 (2014)

7. A-N. Ta, Phd thesis (2009)

8. G.E. Harbeck Jr., M.A. Kohler, G.E. Koberg, U.S. Dept. of the Interior, Geological Survey, (1958)

9. P. Gerard, M. Mahdad, A. Robert McCormack, B.Francois, Constr. Build. Mater. 95, 437-447 (2015)

10. L.A. Richards, Soil Sci. 51, 377-385 (1941)

11. P. Delage, M.D. Howat, Y.J. Cui, Eng. Geol. 50, 31 48 (1998)

12. M.T. Van Genuchten, Soil Sci. Soc. Am. J. (1980)

13. N. Prime, Z. Housni, L. Fraikin, A. Léonard, R. Charlier, S. Levasseur, Transport Porous Med. 106(1), 47-72 (2015)

14. I.C. Kemp, B.C. Fyhr, S. Laurent, M.A. Roques, C.E. Groenewold, E. Tsotsas, A.A. Sereno, C.B. Bonazzi, J.J. Bimbenet, M. Kind, Dry. Technol. 19(1), 15-34 (2001)

15. G.W. Wilson, D.G. Fredlund, and S.L. Barbour, Can. Geotech. J. (1994)

16. A. Léonard, Phd Thesis (2002)

17. P. Gerard, A. Léonard, J.P. Masekanya, R. Charlier, F. Collin, Int. J. Numer. Anal. Met. (2010)

18. Ewen \& Thomas, Géotechnique. 3, 455-470 (1989)

19. Nadeau \& Puiggali, Technique et Documentation Lavoisier: Paris (1995)

20. P. Lehmann, S. Assouline, D. Or, Phys. Rev. E. 77, 056309 (2008)

21. Y. Mualem, Water Resour. Res. 12(3), 513-522 (1976)

22. M. Prat, Int. J. Multiphas. Flow. 21(5), 875-892. (1995)

23. J.B. Laurindo, M. Prat, Chem. Eng. Sci. 51(23), 5171-5185 (1996) 